\title{
A Kinetic Assay for Drug Discovery: Part 2, Sodium Sulfate
}

\author{
Kristel Crocker, Jonie Deleon, Lucy Telliyan, Kevin Aprelian, Aryeh Rosenberg, Nikole Pouri, \\ Gerard Beltran, Vivian Ramirez, David Kaufman, Arpineh Petrosyan, Deanna Nazarian, \\ Monikajane Magistrado, Suren Matinian, Daniel Hanna, Sera Eskandari, Faisal Atanante, \\ Adees Nerses, Greg Zem, Steven Oppenheimer*
}

Department of Biology and Center for Cancer and Developmental Biology, California State University Northridge, Northridge, California, United States

\author{
Email address: \\ kristeljoy.crocker.271@my.csun.edu (K. Crocker), jonie.deleon.993@my.csun.edu (J. Deleon), lucy.telliyan.865@my.csun.edu (L. Telliyan), \\ kevin.aprelian.553@my.csun.edu (K. Aprelian), aryeh.rosenberg.349@my.csun.edu (A. Rosenberg), \\ nikole.pouri.14@my.csun.edu (N. Pouri), gerard.beltran.946@my.csun.edu (G. Beltran), vivian.ramirez.479@my.csun.edu (V. Ramirez), \\ david.kaufman.988@my.csun.edu (D. Kaufman), arpineh.petrosyan.558@my.csun.edu (A. Petrosyan), \\ deanna.nazarian.494@my.csun.edu (D. Nazarian), monikajane.magistrado.635@my.csun.edu (M. Magistrado), \\ suren.matinian.530@my.csun.edu (S. Matinian), daniel.hanna.741@my.csun.edu (D. Hanna), \\ sera.eskandari.487@my.csun.edu (S. Eskandari), faisal.atanante.261@my.csun.edu (F. Atanante), \\ adees.nerses.444@my.csun.edu (A. Nerses), gzem@lausd.net (G. Zem), steven.oppenheimer@csun.edu (S. Oppenheimer) \\ ${ }^{*}$ Corresponding author
}

\section{To cite this article:}

Kristel Crocker, Jonie Deleon, Lucy Telliyan, Kevin Aprelian, Aryeh Rosenberg, Nikole Pouri, Gerard Beltran, Vivian Ramirez, David Kaufman, Arpineh Petrosyan, Deanna Nazarian, Monikajane Magistrado, Suren Matinian, Daniel Hanna, Sera Eskandari, Faisal Atanante, Adees Nerses, Greg Zem, Steven Oppenheimer. A Kinetic Assay for Drug Discovery: Part 2, Sodium Sulfate. American Journal of Applied Scientific Research. Vol. 6, No. 2, 2020, pp. 39-42. doi: 10.11648/j.ajasr.20200602.12

Received: March 31, 2020; Accepted: April 17, 2020; Published: April 30, 2020

\begin{abstract}
Clumped cells are generally more dangerous than single cells in cancer spread, thrombocytosis and biofilm infectivity. Here a simple direct kinetic assay is used to examine a specific reagent for anti-clumping activity using a Prefer fixed yeast (Saccharomyces cerevisiae) model that has been recently described by us in detail using other reagents. In 1212 trials by 17 investigators sodium sulfate (1-3 mg per $\mathrm{ml}$ deionized water) was examined by measuring percentage single cells, number of clumps and number of cells per clump over a 60 min time course, with standard deviations and t-tests to determine any significant differences between controls and experimentals. Sodium sulfate showed sometimes inconsistent unclumping activity especially in magnitude of effects. When percentage of single cells increased, clump number and/or number of cells per clump generally decreased, helping to validate the assay. An example of these findings in 60 trials at $60 \mathrm{~min}$ with $1-3 \mathrm{mg}$ sodium sulfate per ml deionized water: $1 \mathrm{mg} 15 \%$ increased singles $(\mathrm{p}<0.01), 29 \%$ decreased clumps $(\mathrm{p}<0.01), 11 \%$ decreased cells per clump $(\mathrm{p}>0.05) ; 2$ mg $12 \%$ increased singles $(p<0.01), 20 \%$ decreased clumps $(p<0.01), 30 \%$ decreased cells per clump $(p<0.01) ; 3$ mg 27\% increased singles $(p<0.01), 36 \%$ decreased clumps $(p<0.01), 28 \%$ decreased cells per clump $(p<0.02)$. Here sodium sulfate showed promise as an anti-cell-clumping reagent together with sodium citrate reported previously in part 1 of this study. Sodium citrate is a known human anticoagulant independently identified with this assay, helping to validate the assay for drug discovery applications.
\end{abstract}

Keywords: Sodium Sulfate Unclumps Cells, Fixed Yeast Model, Kinetic Assay, Drug Discovery

\section{Introduction}

Cancer cells in clusters are more dangerous than single cells in metastasis [1-5] It is unclear why this is the case but cells in clusters in the bloodstream may express proteins, DNA alterations, and metabolic changes that may promote 
cell survival in clumps. The cellular basis of metastasis has been studied for decades [1-11].

When cancer cell clusters are dissociated into single cells, DNA sites are altered and metastasis is suppressed [10].

Therefore, there is good reason to seek reagents that disaggregate cancer cell clusters. In fact, disaggregating cell clumps could also help prevent and treat thrombocytosis in heart disease and stroke and infectivity of biofilms [12, 13].

In 2015 we reported preliminary results in abstract form that suggested that sodium sulfate may disaggregate cell clumps in a model fixed yeast system [14]. More recently in part 1 of this study we showed that sodium citrate helped disaggregate cell clumps [15]. These results helped confirm the validity of the assay used here, as sodium citrate was previously shown to do this using other methods [12].

In this paper, part 2 of a study presented previously in this journal [15], a detailed report is presented on the effects of sodium sulfate on populations of single cells and cell clusters using a manual kinetic assay that can be considered a gold standard in examining the effects of reagents on cell clumps [15]. It is a gold standard because it is a direct observation kinetic assay and not a faster automated assay that, however, can quickly assess huge numbers of samples [16].

\section{Experimental Procedure}

Yeast fixed with Prefer (Anatech Ltd., Battle Creek, MI) were tested at $0 \mathrm{mg}$ (control), 1, 2 and $3 \mathrm{mg}$ sodium sulfate per $\mathrm{ml}$ deionized water in droplets on glass microscope slides over a 60 min time course and observed with light microscopes with intermittent stirring [15]. Percentages of single cells were calculated as were number of clumps and number of cells per clump in controls and experimentals. Results were plotted with SD bars and 2 tailed $t$ tests were conducted to suggest any significant differences $(\mathrm{p}<0.05)$ between control and experimental results.

\section{Results and Discussion}

1212 trials were conducted by 17 investigators. The reagent sometimes showed variable unclumping activity especially with respect to magnitude of effects. There was clear consistency in the correlation between percent singles and clump characteristics. When percentage of singles increased, number of clumps and/or number of cells per clump generally decreased. These results help validate the simple concept of this assay in suggesting that as clumps disaggregate, percent of single cells increases.

An example of these findings is shown in the figures using sodium sulfate in 60 trials.

See Figures 1-9.

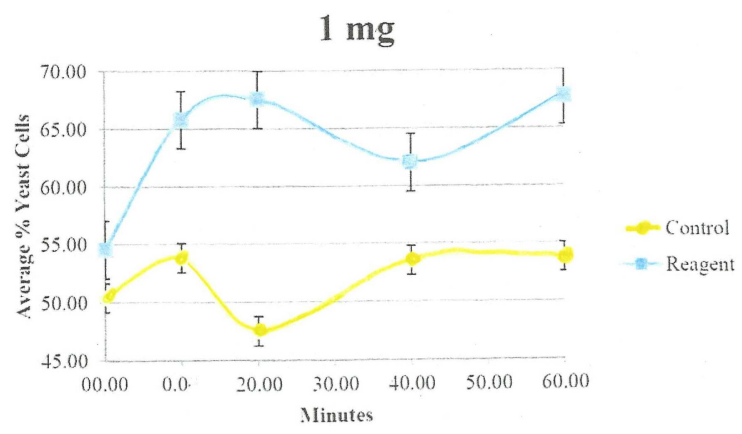

Figure 1. Kinetic Analysis.

$1 \mathrm{mg}$ sodium sulfate per $\mathrm{ml}$ deionized water:

$15 \%$ increased singles over controls $(\mathrm{p}<0.01), 60 \mathrm{~min}$.

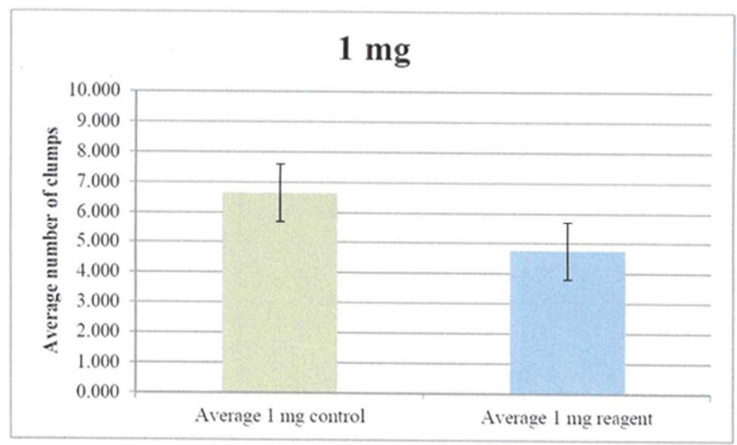

$29 \%$ decreased clumps over controls $(\mathrm{p}<0.01), 60 \mathrm{~min}$.

Figure 2. Number of clumps, $1 \mathrm{mg}$.

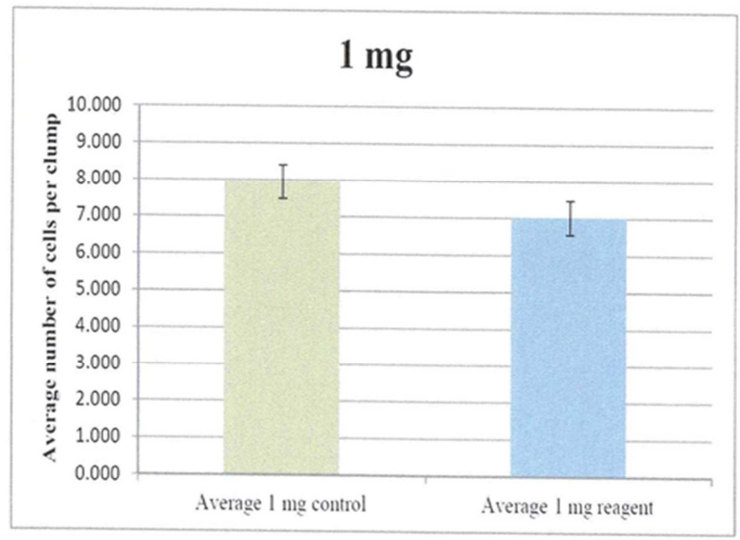

Figure 3. $11 \%$ decreased cells per clump over controls ( $p>0.05), 60 \mathrm{~min}$.

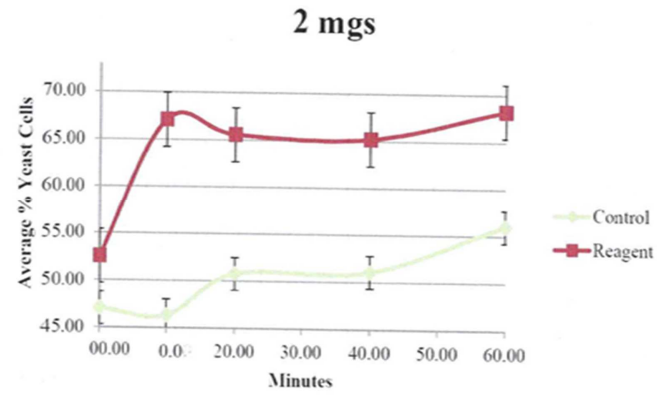

Figure 4. Kinetic analysis.

$2 \mathrm{mg}$ sodium sulfate per $\mathrm{ml}$ deionized water:

$12 \%$ increased singles $(\mathrm{p}<0.01), 60 \mathrm{~min}$; 


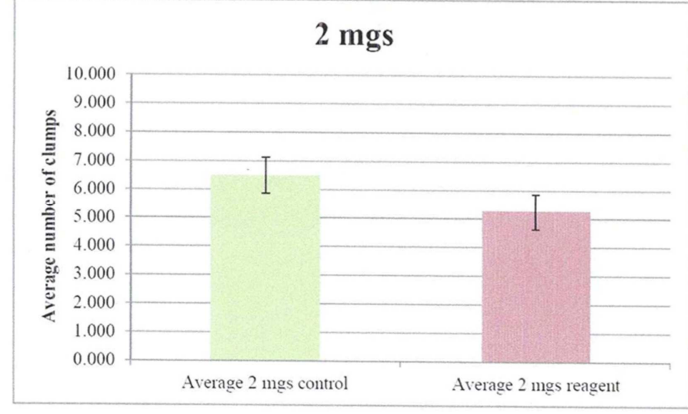

$20 \%$ decreased clumps $(\mathrm{p}<0.01) 60 \mathrm{~min}$

Figure 5. Number of clumps, $2 \mathrm{mg}$.

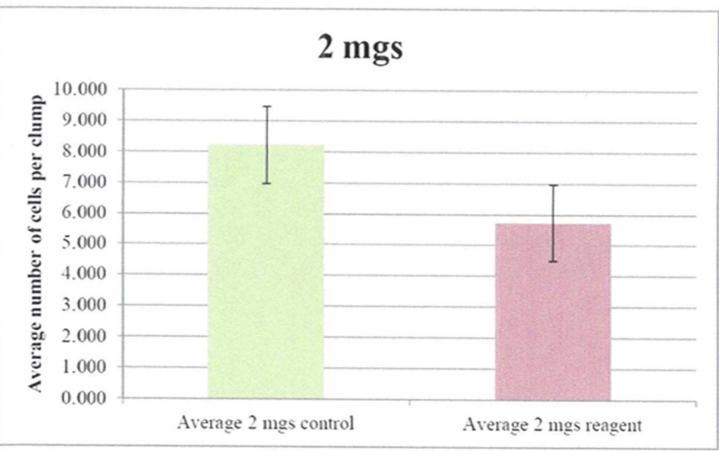

$30 \%$ decreased cells per clump $(\mathrm{p}<0.01), 60 \mathrm{~min}$

Figure 6. Cells per clump, $2 m g$.

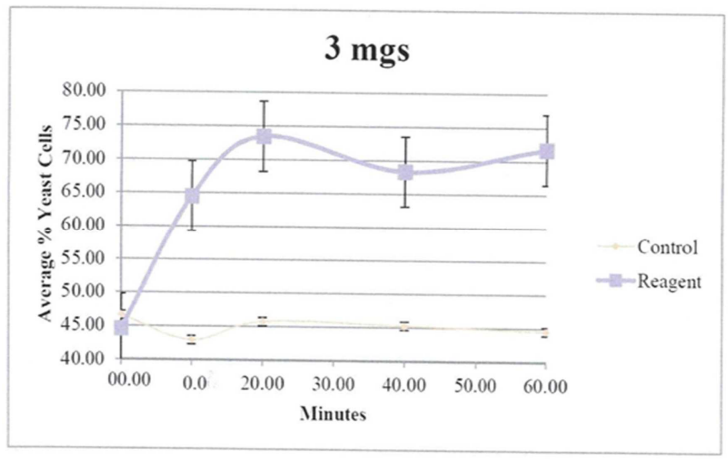

Figure 7. Kinetic analysis.

$3 \mathrm{mg}$ sodium sulfate per $\mathrm{ml}$ deionized water.

$27 \%$ increased singles $(\mathrm{p}<0.01), 60 \mathrm{~min}$

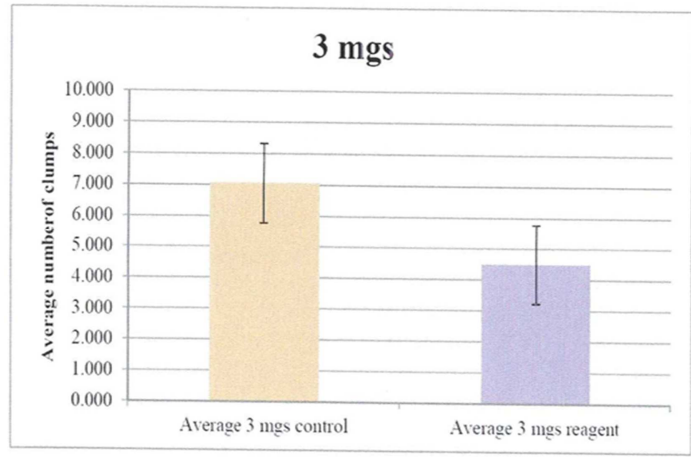

$36 \%$ decreased clumps (p,0.01), $60 \mathrm{~min}$.

Figure 8. Number of clumps, $3 \mathrm{mg}$.

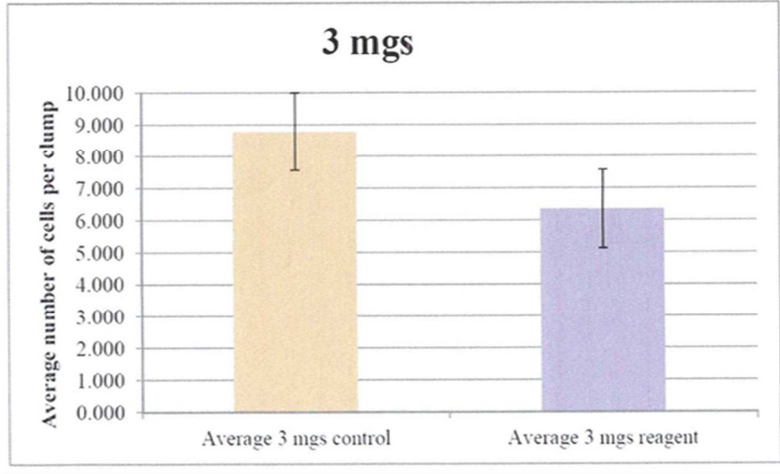

$28 \%$ decreased cells per clump $(\mathrm{p}<0.02), 60 \mathrm{~min}$.

Figure 9. Cells per clump, $3 \mathrm{mg}$.

These results suggest a concentration dependent effect on reducing cell clumping with sodium sulfate, where as single cell populations increase, clumps decrease. This is to be expected but it is important to demonstrate this statistically as done here.

In a recent paper, part 1 of this study [15] this lab showed that sodium citrate exhibited anti-cell clumping effects. As sodium citrate is a known anti-coagulant [12] that was demonstrated using other assays, our independent finding of sodium citrate's anti-clumping activity using the assay used here, helps validate this assay as possibly useful in drug discovery applications.

Here, using this assay, sodium sulfate is also identified as a likely anti-clumping reagent.

This manual kinetic assay uses direct observations over time with light microscopes. This allows scores of investigators to gather data with precise statistical evaluations.

Steve Oppenheimer, Fellow American Association for the Advancement of Science, a co-author here, was presented with a U.S. Presidential Award for Mentoring by the White House and National Science Foundation based on involving hundreds of students in research and assessing their career outcomes [17-19]. This kinetic assay lends itself to introducing many students to statistically evaluated published research.

\section{Conclusions}

Sodium sulfate is identified as a potential cell cluster unclumping agent that could be of value in reducing cell clumps in cancer metastasis, thrombocytosis and biofilm infectivity. The kinetic assay reported here can be considered to be a gold standard for precise assessment of potential anticlumping agents and can be used in many training and research applications.

\section{Acknowledgements}

We thanks Carolyn Oppenheimer for expert assistance with the figures. This work was supported by California State University, Northridge, Department of Biology and Center for Cancer and Developmental Biology. 


\section{References}

[1] F. Castro-Giner, N. Aceto Tracking cancer progression: from circulating tumor cells to metastasis Genome Med, 12 (2020) pp. 31-57.

[2] N. Aceto, A. Bardia, D. T. Miyamoto, M. C. Donaldson, B. S. Wittner, J. A. Spencer, M. Yu, A. Pely, A. Engstrom, H. Zhu, B. W. Brannigan, R. Kapur, S. L. Stott, T. Shioda, S. Ramaswamy, D. T. Ting, C. P. Lin, M. Toner, D. A. Haber, S. Maheswaran Circulating tumor cell clusters are oligoclonal precursors of breast cancer metastasis Cell 158 (2014), pp. 1110-1122.

[3] C. F. Laqbuschagne, E. C. Cheung, J. Blagih, M. C.. Domart, K. H. Vousden Cell clustering promotes a metabolic switch that supports metastatic colonization Cell Metab 30 (2019), pp. 720-734.

[4] I. J. Fidler The relationship of embolic homogeneity, number, size and visability to the incidence of experimental metastasis Eur J Canceer 9 (1973), pp. 223-227.

[5] I. J. Fidler The pathogenesis of cancer metastasis: the seed and soil hypothesis revisited Nat Rev Cancer 3 (2003), pp. 453458.

[6] I. Zeidman, J. M. Buss Transpulmonary passage of tumor cell emboli Cancer Res 12 (1952), pp. 731-733.

[7] L. A. Liotta, M. G. Saidel, J. Kleinerman The significance of hematogenous tumor cell clumps in the metastatic process Cancer Res 36 (1976), pp. 889-894.

[8] V. Padmanaban, I. Krol, Y. Suhail, B. M. Szczerba, N. Aceto, J. S. Bader, A. J. Ewald E-cadherin is required for metastasis in multiple models of breast cancer Nature 573 (2019), pp. 439-444.

[9] M. E. Menyailo, M. S. Tretyakova, E. V. Denisov Heterogeneity of circulating tumor cells in breast cancer: identifying metastatic seeds Int. J. Mol. Sci 21 (2020), pp. 1696-1712.

[10] S. Gkountela, F. Castro-Giner, B. M. Szczerba, M. Vetter, J. Landin, R. Scherrer, I. Krol, M. C. Schneidmann, C. Beisel, C. U. Stirnimann, C. Kurzeder, Vheinzelnann-Schwarz, C. Rochlitz, W. P. Weber, N. Aceto Circulating tumor cell clustering shapes DNA methylation to enable metastasis seeding Cell 176 (2019) pp. 98-112.

[11] S. B. Oppenheimer Cellular basis of cancer metastasis Acta Histochem 108 (2006), pp. 327-334

[12] K. Germanovich, E. Allesandra Femiaq, C. Y. Cheng, N. Dovlatova, M. Cattaneo Effects of $\mathrm{pH}$ and concentration of sodium citrate anticoagulant on platelet aggregation measured by light transmission aggregometry induced by adenosine diphosphate Platelets 29 (2018) pp. 21-26.

[13] Kolodkin-Gal, S. Romero, S. Cao, J. Clardy, R. Kolter, R. Losick D-amino acids trigger biofilm disassembly Science 30 (2010), pp. 627-629.

[14] G Zem, O Tosunyan, A Hambarsoomian, K Lim, K Khatiblou, S Niamat E Choi, C Monroy, M Chavez, N Karaan, M Basmajian, S Kim, A Kurginyan, S Sorooshian, L Manzo, F Bahri,. A Holverson, G Chacon, N Allatabakhsh, C Irikyan, C Tortorice, S Balyan, N Amer, S Shtivelman, V Vahdati, T Kaur S Danialian, A Allard, L Jorshari, N Kazmi, N Sarkissian, K Mkhitarian, C Chavez, M Havaei, A Adzhemian, M Takakura, Y Huang, A Haritounian, A Arakelian, J Bohorquez, M Asatryan, Y Herrera, L Mayorga, A Garcia, S Oppenheimer Heirarchy of anti-clumping salts FASEB J 29 (2015), abstract id 52.

[15] V. Nahapetyan, S. Delos Santos, K. J. Crocker, D. Tobar, D. Nazarian, H. Chirishyan, G. Beltran, R. Dubin, L. Reque,, P. Singh, B. Cardona, G. Royce Bachinela, L. Sarkisyan, G. Zem, S. Oppenheimer A manual kinetic assay in a fixed yeast model for drug discovery American Journal of Applied Scientific Research 5 (2019) pp. 28-35.

[16] P. C. Zeidler-Erdely, J. M. Antonino, T. G. Meighan, S. H. Young, T. J. Eve, M. A. Hammer, A Erdely Comparison of cell counting methods in rodent pulmonary toxicity studies: automated and manual protocols and considerations for experimental design Inhal Toxicol 28 (2016), mpp. 410-420.

[17] S. B. Oppenheimer Lab training: undergraduate research in action Nature 519 (2015), p. 158.

[18] O. Herstein Steven Oppenheimer CSUN Magazine 67 (2016) p. 20.

[19] National Science Foundation, Presidential awards for excellence in science, mathematics and engineering mentoring NSF Home Page (2019). This is the highest U.S. national award for mentoring. 